\title{
Desenvolvendo um questionário para validação de programas voltados para pessoas portadoras do TEA \\ Victória Oliveira Gomes ${ }^{1}$; Victor Travassos Sarinho \\ 1. Bolsista PEVIC, Graduando em Engenharia de Computação, Universidade Estadual de Feira de Santana, e-mail: victoria.oliveiragomes@gmail.com \\ 2. Orientador, Departamento de Exatas, Universidade Estadual de Feira de Santana, e-mail: vsarinho@gmail.com
}

PALAVRAS-CHAVE: questionário; TEA; jogos digitais.

\section{INTRODUÇÃO}

Indivíduos portadores do Transtorno do Espectro Autista (TEA) possuem certas características e peculiaridades que devem analisadas e consideradas ao desenvolver softwares e aplicações. Isso fornecerá uma base para que os desenvolvedores saibam previamente as respostas que tais pessoas irão fornecer quando dados estímulos específicos.

A criança pode, por exemplo, apresentar comportamentos obsessivos e ritualísticos, como o apego à rotina rígida e a obsessão por objetos, enquadrando-se estes na dificuldade de imaginação, que se estende às várias áreas do pensamento e prejudica claramente qualquer tentativa de transmissão de conhecimento (Mello, 2001). Tais características do espectro tornam o aprendizado de crianças autistas um processo difícil (Farias, 2013).

Os profissionais encarregados pela terapia das crianças que possuem tal transtorno e os pais e responsáveis que convivem com as mesmas podem ser auxiliados largamente com a utilização da tecnologia. Jogos, por exemplo, são excelentes para transmissão de conteúdo. Eles prendem a atenção da criança com mais eficácia e promovem um aprendizado mais prazeroso, uma vez que proporcionam um ambiente de imersão e interatividade (Aranha, 2006).

Assim, o desenvolvimento de um questionário para validar se um jogo é passível de ser utilizado com indivíduos portadores do TEA visa justamente possibilitar que os benefícios acima descritos sejam alcançados. Seu desenvolvimento é importante para que não haja retrocesso ao utilizar esses games com as crianças, uma vez que, dada as peculiaridades que acometem esses indivíduos, é fundamental que certos cuidados sejam tomados.

\section{MATERIAL E MÉTODOS OU METODOLOGIA}

Para validar jogos voltados para crianças portadoras do Transtorno do Espectro Autista (TEA), é necessário, inicialmente, compreender o universo das mesmas. Foram feitos alguns levantamentos bibliográficos buscando entender as peculiaridades características dos indivíduos portadores do TEA e as metodologias que devem ser utilizadas para promover o aprendizado dos mesmos. 
Além disso, buscou-se algumas informações acerca do desenvolvimento de jogos digitais voltados especificamente para os indivíduos que vivem nesse espectro. Nisso, verificou-se a ausência de uma quantidade satisfatória de esforços e pesquisas visando obter avanços nessa área do conhecimento em específico.

A partir dessas informações levantadas, foram confeccionadas as questões que compõe o questionário desenvolvido. Ele busca verificar e validar jogos para serem utilizados por portadores do TEA. O mesmo consiste em uma série de perguntas genéricas que avaliam quesitos desde a distribuição espacial dos elementos no jogo até a trilha sonora do mesmo.

\section{RESULTADOS E/OU DISCUSSÃO (ou Análise e discussão dos resultados)}

Desenvolveu-se um questionário com 7 questões, como visto na tabela 1. Ao considerar a resposta de cada uma delas em conjunto, é possível definir se um jogo é passível de ser utilizado por indivíduos portadores do TEA.

Tabela 1. Perguntas do questionário desenvolvido.

\begin{tabular}{cl} 
ID & \multicolumn{1}{c}{ Perguntas } \\
\hline 1 & Qual a incidência de elementos distrativos no jogo? \\
2 & Existe aspecto educativo voltado para portadores do TEA? \\
3 & De que maneira o jogo recompensa/pune o jogador? \\
4 & Por quanto tempo se repete uma "competência" do jogo? \\
5 & Existe explicação de como o jogo funciona ao iniciá-lo? \\
6 & Exige boa coordenação motora? \\
7 & Existe uma divisão espacial na organização dos elementos do jogo?
\end{tabular}

Para verificar e exemplificar a validade do questionário, o mesmo foi aplicado em alguns jogos voltados para o TEA. Os games selecionados fazem parte da iniciativa Whiz Kids, e são eles: Ron Gets Dressed, Rufus Goes to School, Ted \& Ice Cream Adventures e Robbie the Robot.

Foi feita uma avaliação qualitativa acerca desses jogos selecionados. Ela foi promovida através das respostas de alguns estudantes: eles escolhiam qual dos quatro jogos desejavam jogar e, após brincar com o mesmo por um determinado período de tempo, eles preenchiam o questionário.

O grupo selecionado para responder as perguntas acerca dos jogos avaliados é constituído de estudantes do ensino superior de uma universidade pública. Os mesmos não possuem conhecimentos específicos acerca do TEA, uma vez que isso não se faz necessário para responder a grande maioria das questões. 
Os resultados alcançados a partir dessa avaliação qualitativa podem ser observados na figura 1. Ao analisar os mesmos, confirmou-se a percepção de transmissão de conhecimento para portadores do TEA, a repetição contínua de competências trabalhadas nos jogos analisados, a existência de uma explanação prévia de funcionamento nestes jogos, e a divisão espacial clara e bem definida dos elementos do jogo.

Para a presença de elementos distrativos em excesso, a representação de um sistema de punição/recompensa, e o nível de exigência de coordenação motora, estes mostraram resultados próximos de um equilíbrio de opiniões, porém ainda favoráveis a confirmação de que tais jogos atendem aos critérios base de jogos TEA previamente definidos.

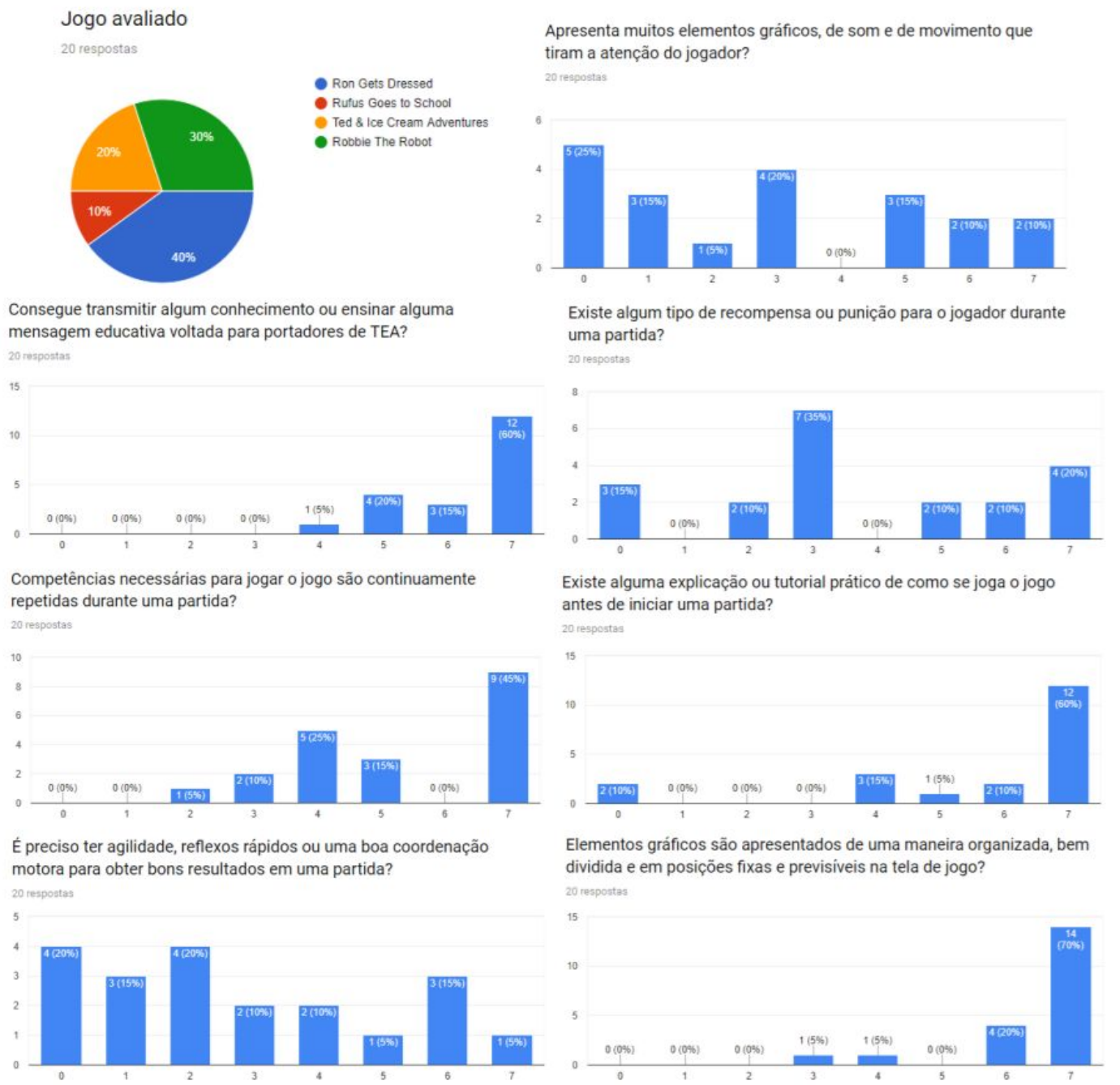

Figura 1: Resultados da pesquisa qualitativa

\section{CONSIDERAÇÕES FINAIS (ou Conclusão)}

O questionário confeccionado, o qual visa uma abordagem para jogos digitais para portadores do Transtorno do Espectro Autista (TEA), foi feito com questões base de avaliação definidas a partir de trabalhos relacionados a educação de tais indivíduos. 
Para validação do mesmo, foram realizadas análises qualitativas nos jogos citados anteriormente, cujas respostas elucidaram os pontos fortes e fracos de cada um dos games no que tange a sua utilização na educação de indivíduos portadores do TEA.

Em relação aos jogos utilizados nas avaliações, deu-se preferência a aqueles que possuíam ênfase em interações sociais e emoções, uma vez que estes mostram de maneira clara os aspectos trabalhados com mais frequência com portadores do TEA.

Assim, o questionário proposto constitui, além de uma metodologia de avaliação para jogos já existentes, para verificar se os mesmos são passíveis de serem usados por portadores do TEA, um guia para produção de jogos educacionais voltados para os mesmos, uma vez que as respostas obtidas com o mesmo demonstraram cobrir os recursos voltados para o TEA em cada um dos jogos analisados.

\section{REFERÊNCIAS}

MELLO, A.M.S. 2001. Autismo: guia prático. In Autismo: guia prático.

FARIAS, E.B.; Cunha, M.X. 2013. Protótipo de uma Ferramenta de Software para Apoio no Tratamento de Crianças com Autismo. Simpósio Brasileiro de Sistemas de Informação, 9, pp.332-342.

ARANHA, G. 2006. Jogos Eletrônicos como um conceito chave para o desenvolvimento de aplicações imersivas e interativas para o aprendizado. Ciências \& Cognição, 7 . 